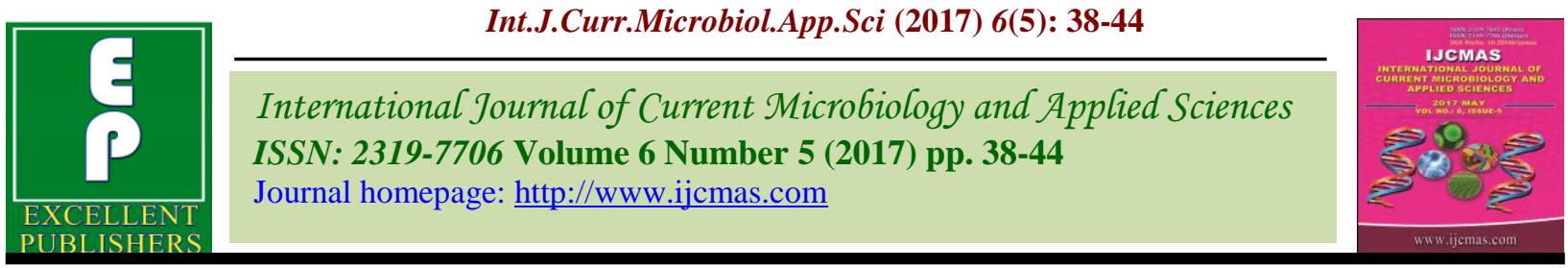

Original Research Article https://doi.org/10.20546/ijcmas.2017.605.005

\title{
Antibacterial Activity of Fruit Methanol Extract of Ziziphus spina-christi from Sudan
}

\author{
Emad Mohamed Abdallah* \\ Department of Laboratory Sciences, College of Sciences and Arts, \\ Qassim University, Al-Rass, Saudi Arabia \\ *Corresponding author
}

\begin{abstract}
A B S T R A C T
\section{Keywords}

Antibacterial activity, Agar-well diffusion, MIC, MBC, Ziziphus spina-christi, Sudan.

Article Info

Accepted:

04 April 2017

Available Online:

10 May 2017

The fruit (Nabag or Christ's Thorn Jujube) of Sidir tree (Ziziphus spina-christi) is a native snack food in Sudan. The antibacterial properties of methanol fruit extract of the Sudanese Ziziphus spina-christi was investigated against different ATCC strains of Gram-positive and Gram-negative bacteria. The agar-well diffusion test, minimum inhibitory concentration (MIC) and minimum bactericidal concentration (MBC) tests were used to evaluate the antibacterial activity. In general, the study revealed that the fruit extract has no antibacterial activity against the Gram-negative bacteria (Escherichia coli ATCC 35218 and Klebsiella pneumoniae ATCC 700603). While, moderate antibacterial activities against the Gram-positive bacteria were recorded. The most sensitive bacteria were Staphylococcus epidermidis ATCC 12228, followed by Staphylococcus aureus ATCC 25923 and Bacillus cereus ATCC 10876, respectively. The least sensitive bacteria were Enterococcus faecalis ATCC 29212. However, the detected activities were not significant compared to the antibiotic (Chloramphenicol $5 \mathrm{mg} / \mathrm{ml}$ ). Further studies using different solvents for extraction alongside with phytochemical and pharmacological studies are necessary to determine the bioactive compounds of the fruits of Ziziphus spina-christi.
\end{abstract}

\section{Introduction}

Plants have been used in the human activities since ancient times as a basic source for food, fuel, shelter, clothing, cosmetics, ceremonies and medicine. People in the current industrial civilization tend to use synthetic medication as well as fast food, rich in nutrients such as carbohydrates, proteins, and fats; while very poor in bioactive phytochemical compounds. Such behavior from the modern humans let them less immunity against pathogenic diseases caused by microorganisms. Nowadays, infectious diseases are the second leading cause of mortality worldwide, where more than $25 \%$ of deaths are caused by infectious diseases (Fauci et al., 2005). Accordingly, human should go back to extract pharmaceuticals from plants and not from synthetic drugs and consume food rich in bioactive compounds. The WHO estimated that up to $80 \%$ of the world population particularly in the developing countries relies mainly on traditional medicine, which is mostly derived from plants (Arvigo and Balick, 1993). Most people in the rural areas in Sudan cannot afford the expenses of modern medicine and totally depend on traditional medicinal plants (Robinson, 2006). Although there are up to 2000 medicinal 
plants in use in Sudanese traditional medicine, However, scientific investigations on their bioactivity are very modest (Abdalla and Abdallah, 2016). Plants are able to produce numerous secondary molecules as part of its survival strategy (Houghton, 2001). The antimicrobial potential of some plants is attributed to the presence of some secondary molecules called phytochemicals such as alkaloids, flavonoids, terpenoids, tannins, saponins, anthraquinones and glycosides (Omojate et al., 2014). The tree of Ziziphus spina-christi L. Desf., family: Rhamnaceae, named in Sudan and the Middle East as Sidr or Sidder (In English: Christ's Thorn Jujube). It is an evergreen spiny shrub (5-10 meters tall), drought and heat tolerant, distributed throughout tropical and subtropical countries in North Africa, Middle East and North West India, this plant is native to Sudan and widespread in central and western parts of the country (Saied et al., 2008).

Ziziphus spina-christi is well known since ancient pharaonic civilization, its fruit is known in hieroglyphic language as nebes (Similar to the current local name in Sudan: Nabag), where it was mentioned in ancient papyri for wound healing and anti-swellings (Kadioglu et al., 2016). In Sudan, the fruits of Ziziphus spina-christi, which is known locally as Nabag are eaten to treat diarrhea and malaria and as an antispasmodic (El-Kamali and El-Khalifa, 1999). Different parts of this plant have been investigated for its bioactivity such as leaves, stem bark and roots, which showed antimicrobial, antioxidant, antinociceptive and antidiabetic effects (Asgarpanah and Haghighat, 2012). However, studies on the fruit of Sudanese Ziziphus spina-christi are not adequate. The present study aimed at evaluating the in vitro antibacterial activity of fruit of Ziziphus spina-christi, widely consumed in Sudan as a popular snack food.

\section{Materials and Methods}

\section{Plant material and extraction}

Dry fruits of Ziziphus spina-christi were purchased from local markets in Khartoum, Sudan. Washed with distilled water, dried with towels and the inner seed was removed, the fruit pulp was separated and kept in a clean dark cupboard for 3 days, ground to a fine powder and macerated in $80 \%$ methanol for up to a week with frequent shaking. Then, filtered twice with Whatman filter paper, the macerate was kept in an incubator at $40{ }^{\circ} \mathrm{C}$ to evaporate the solvent for up to 2 weeks until getting dry extract. The crude dry extract was reconstituted in $10 \%$ Dimethyl sulfoxide (DMSO) to make two different concentration $500 \mathrm{mg} / \mathrm{ml}$ and $250 \mathrm{mg} / \mathrm{ml}$.

\section{Microorganisms}

Six referenced bacterial strains representing different Gram-positive and Gram-negative bacteria were used in this study. The tested Gram-positive bacteria were Staphylococcus aureus ATCC 25923, Staphylococcus epidermidis ATCC 12228, Enterococcus faecalis ATCC 29212 and Bacillus cereus ATCC 10876. While the tested Gramnegative bacteria were Klebsiella pneumoniae ATCC 700603 and Escherichia coli ATCC 35218 .

\section{Antimicrobial activity}

The antibacterial activity of the methanol extract of Ziziphus spina-christi fruit was evaluated by means of the agar-well diffusion assay as mentioned in (Güven et al., 2006). 20 $\mathrm{ml}$ of molten Mueller-Hinton agar $\left(45^{\circ} \mathrm{C}\right)$ was poured into sterile Petri dish. $100 \mu \mathrm{l}$ of the microbial suspension containing approximately $10^{8} \mathrm{CFU} / \mathrm{ml}$ bacteria was loaded on the plate and spread using a sterile cotton swab. The plate was left to dry 
aseptically at room temperature for up to 15 minutes. A $6 \mathrm{~mm}$ diameter wells were made on the agar plate using a sterile cork borer and subsequently $50 \mu \mathrm{l}$ of the methanolic extract that was reconstituted before in $10 \% \mathrm{DMSO}$ at two different concentrations; $500 \mathrm{mg} / \mathrm{ml}$ and $250 \mathrm{mg} / \mathrm{ml}$ were placed into the wells. Chloramphenicol $0.5 \% \mathrm{w} / \mathrm{v}(5 \mathrm{mg} / \mathrm{ml})$ was also loaded in wells and used as standard antibiotic. The pre-experimental test showed that $10 \%$ DMSO has no inhibitory effect on bacterial growth. The plates were then incubated at $37^{\circ} \mathrm{C}$ for $24 \mathrm{~h}$. The experiment was repeated twice and the mean zone of inhibition against the test organism was calculated.

\section{Determination of minimum inhibitory concentration (MIC)}

MIC test was performed on bacteria, which showed sensitivity against the methanol extract from above $10 \mathrm{~mm}$ zone of inhibition using the broth dilution method as reported by El-Mahmood and Ameh (2007) with minor modifications. Firstly, test tubes containing 1 $\mathrm{ml}$ of Mueller-Hinton broth were prepared and autoclaved. Then, $1 \mathrm{ml}$ of the plant's extract at a concentration of $200 \mathrm{mg} / \mathrm{ml}$ was poured into a test tube. Subsequently, serial two-fold dilutions were made by transferring $1 \mathrm{ml}$ from the first tube after shaking well to another $1 \mathrm{ml}$ Mueller-Hinton broth tube and so on, giving extract concentrations of 200 , $100,50,25,12.5,6.25$ and $3.123 \mathrm{mg} / \mathrm{ml}$. Another $1 \mathrm{ml}$ of fresh referenced microbial strain was poured to each concentration. In addition, to another two Mueller-Hinton broth tube $1 \mathrm{ml}$ of antibiotic (Chloramphenicol $5 \mathrm{mg} / \mathrm{ml}$ ) was poured to serve as a positive control, and $1 \mathrm{ml}$ of $10 \%$ DMSO to serve as a negative control. All test tubes were incubated at $37^{\circ} \mathrm{C}$ for $24 \mathrm{~h}$. The tube with the lowest dilution with no visible growth was considered as the MIC.

\section{Determination of minimum bactericidal concentration $(\mathrm{MBC})$}

The MBC test was evaluated following the method reported by Doughari (2006) with slight modification. Directly after the MIC testing, $100 \mu \mathrm{l}$ from the MIC tubes that showed no visible growth was decanted on the surface of plates containing autoclaved Mueller-Hinton agar. To another 2 MuellerHinton plates, $100 \mu \mathrm{l}$ from the MIC tube containing chloramphenicol was decanted on the surface of Mueller-Hinton agar plate to serve as negative control and $100 \mu \mathrm{l}$ from the MIC tube containing $10 \%$ DMSO was decanted on the surface of another MuellerHinton agar plate to serve as negative control. All inoculated plates were then incubated for about 18 hours at $37{ }^{\circ} \mathrm{C}$ and investigated for bacterial growth. Plates with no visible growth were considered to be the $\mathrm{MBC}$ for the plant extract.

\section{Statistical analysis}

Data were expressed as Mean \pm standard error of means; the statistical software used was SPSS (v.16.0).

\section{Results and Discussion}

Results of the agar-well diffusion test showed that the methanol fruit extract of Ziziphus spina-christi has varied degrees of antibacterial effects on the Gram-positive bacteria and no effect on the Gram-negative bacteria (Table 1 and Figures 1 and 2). At the concentrations $500 \mathrm{mg} / \mathrm{ml}$ and $250 \mathrm{mg} / \mathrm{ml}$, the most sensitive bacteria was Staphylococcus epidermidis ATCC 12228 (11.0 \pm 1.0 and 10.5 $\pm 0.5 \mathrm{~mm}$ ), followed by Staphylococcus aureus ATCC 25923 (11.0 \pm 0.0 and $7.7 \pm 0.7$ $\mathrm{mm})$, and Bacillus cereus ATCC 10876 (10.5 \pm 0.5 and $8.2 \pm 0.7 \mathrm{~mm}$ ), respectively. The least sensitive bacteria was Enterococcus faecalis ATCC $29212(8.0 \pm 1.0$ and $6.7 \pm 0.2$ 
$\mathrm{mm})$, respectively. However, the detected activities were not significant compared to the antibiotic (Chloramphenicol $5 \mathrm{mg} / \mathrm{ml}$ ) which showed obvious inhibitory effects against all the tested bacteria. On the other side, Gramnegative bacteria was not susceptible toward the fruit extract but sensitive to the antibiotic, where both of Escherichia coli ATCC 35218 and Klebsiella pneumoniae ATCC 700603 recorded $6.0 \pm 0.0 \mathrm{~mm}$ against the fruit extract (the diameter of the hole is $6 \mathrm{~mm}$ ). Leaves and some other parts of Ziziphus spp. were exhaustively studied, but studies on the fruits are scant. The findings of the current study are in agreement-in partial-with the results of (Ali et al., 2015), both showed antibacterial activity against the Gram-positive bacteria, but our study did not detect antibacterial effect against the Gram-negatives. Actually, varied results of antibacterial and antifungal activity of the fruit of Ziziphus spina-christi were published. Tom et al., (2009) cited that the aqueous extract of the pulp (fruit) of Ziziphus spina-christi has antibacterial potential against Escherichia coli, Pseudomonas aeruginosa (Gram-negatives) and antifungal potency against Candida albicans. While, our study showed no effect against Escherichia coli (Ali et al., 2015) mentioned that methanol extract of Ziziphus spina-christi has no antifungal effects against either Aspergillus niger or Candida albicans. Geographical and environmental variations may affect on the bioactive constituents of the same plant species. Therefore, on the lack of adequate information, consecutive studies on the fruit of Ziziphus spina-christi using different solvents and antibacterial methods would clarify the contradicted findings.

Table.1 The antibacterial activity of the methanol fruit extract of Ziziphus spina-christi

\begin{tabular}{|l|c|c|c|c|c|c|}
\hline \multirow{2}{*}{$\begin{array}{l}\text { Tested } \\
\text { Compound }\end{array}$} & \multicolumn{5}{|c|}{ Mean zone of growth inhibition in mm* } \\
\cline { 2 - 7 } & Sa & Se & Ef & Bc & Ec & kp \\
\cline { 2 - 6 } & $11.0 \pm 0.0$ & $11.0 \pm 1.0$ & $8.0 \pm 1.0$ & $10.5 \pm 0.5$ & $6.0 \pm 0.0$ & $6.0 \pm 0.0$ \\
\hline $\begin{array}{l}\text { Methanol extract } \\
500 \mathrm{mg} / \mathrm{ml}\end{array}$ & & & & & & $6.0 \pm 0.0$ \\
\hline $\begin{array}{l}\text { Methanol extract } \\
250 \mathrm{mg} / \mathrm{ml}\end{array}$ & $7.7 \pm 0.7$ & $10.5 \pm 0.5$ & $6.7 \pm 0.2$ & $8.2 \pm 0.7$ & $6.0 \pm 0.0$ & $6.0 \pm 0.0 \pm 0.5$ \\
\hline $\begin{array}{l}\text { Chloramphenicol } \\
5 \mathrm{mg} / \mathrm{ml}\end{array}$ & $40.5 \pm 0.5$ & $29.5 \pm 0.5$ & $31.0 \pm 1.0$ & $31.0 \pm 0.0$ & $22.5 \pm 0.5$ & $23.5 \pm 0.5$ \\
\hline $10 \%$ DMSO & $6.0 \pm 0.0$ & $6.0 \pm 0.0$ & $6.0 \pm 0.0$ & $6.0 \pm 0.0$ & $6.0 \pm 0.0$ & $6.0 \pm 0.0$ \\
\hline
\end{tabular}

*Disc diameter $=6.0 \mathrm{~mm}, 6.0 \pm 0.0=$ No activity (the disc diameter), Zone of inhibition is the mean of two replicates \pm standard error of means, $\mathrm{Sa}=$ Staphylococcus aureus ATCC 25923, $\mathrm{Se}=$ Staphylococcus epidermidis ATCC 12228, $\mathrm{Ef}=$ Enterococcus faecalis ATCC 29212, $\mathrm{Bc}=$ Bacillus cereus ATCC 10876, Ec=Escherichia coli ATCC 35218, $\mathrm{Kp}=$ Klebsiella pneumoniae ATCC 700603, DMSO= Dimethyl sulfoxide.

Table.2 The MIC and MBC tests of the methanol fruit extract of Ziziphus spina-christi

\begin{tabular}{|l|c|c|}
\hline Microorganism & MIC (mg/ml) & MBC (mg/ml) \\
\hline Staphylococcus aureus ATCC 25923 & 100 & 200 \\
\hline Bacillus cereus ATCC 10876 & 100 & $<200$ \\
\hline Staphylococcus epidermidis ATCC 12228 & 50 & 200 \\
\hline
\end{tabular}


Fig.1 Representative Photo showing fruits of the Sudanese Ziziphus spina-christi and antibacterial effect; A: The fruits (Nabag), B: Its antibacterial activity

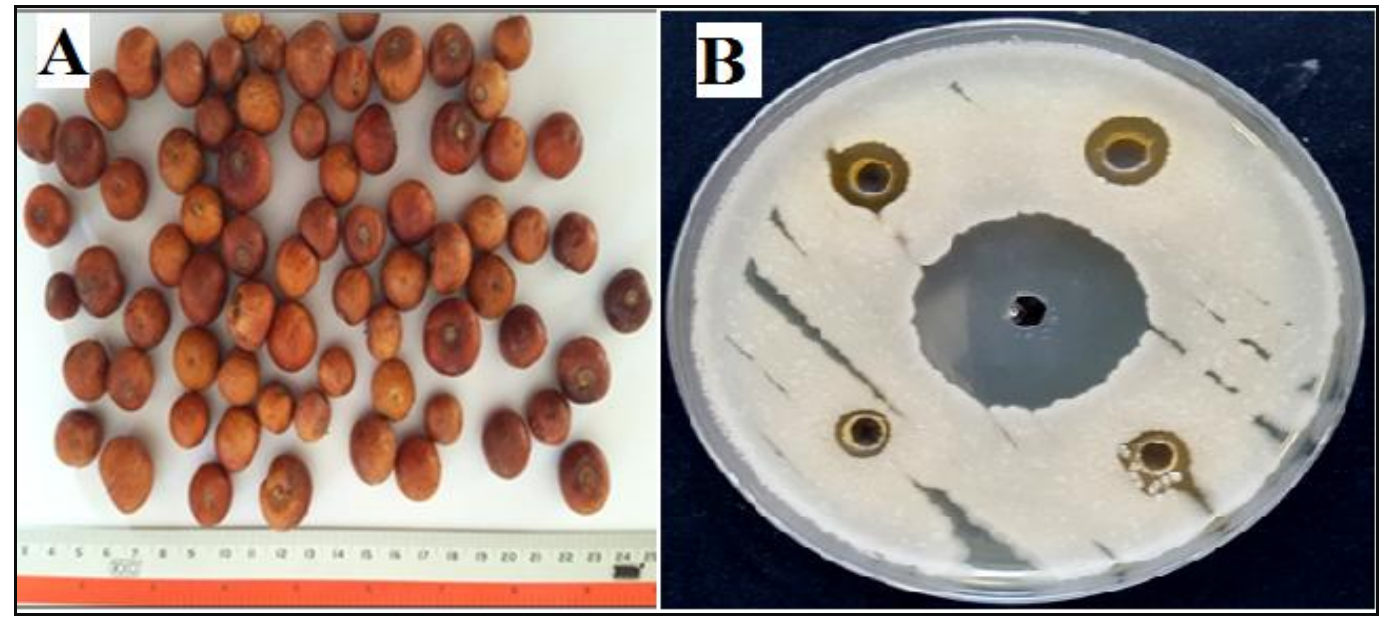

Fig.2 Sensitivity of bacterial strains toward fruits of Ziziphus spina-christi compared to chloramphenicol

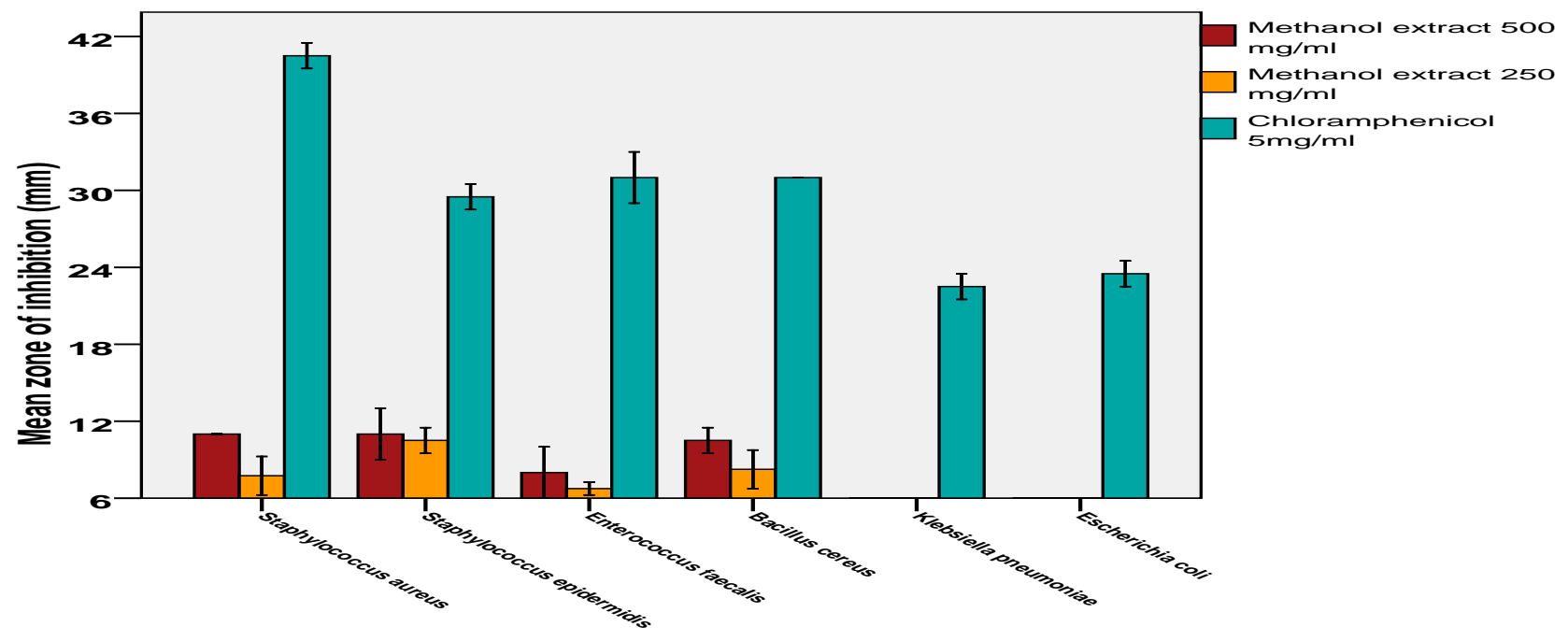

The results of the MIC and MBC values are shown in (Table 2). Only bacteria that showed inhibition zone with the cup-plate diffusion assay were tested. Low MIC values indicate high antibacterial effect (Rios et al., 1988). Accordingly, The MIC values showed that the lowest level of antibacterial agent from the fruit extract of Ziziphus spina-christi that inhibit the growth of bacteria was ranging between $(50-100 \mathrm{mg} / \mathrm{ml})$. The most affected bacteria was Staphylococcus epidermidis
ATCC $12228(50 \mathrm{mg} / \mathrm{ml})$, followed by both of Staphylococcus aureus ATCC 25923 and Bacillus cereus ATCC 10876 which recorded $(100 \mathrm{mg} / \mathrm{ml})$. The MBC values demonstrate the lowest level of antimicrobial agent that results in microbial death, meaning that, even if a particular MIC shows inhibition, plating the bacteria onto agar might still result in organism proliferation because the antimicrobial did not cause death. Antibacterial agents are generally considered 
as bactericidal if the $\mathrm{MBC}$ is no more than four times the MIC. Accordingly, the methanol fruit extract of Ziziphus spinachristi has a bactericidal nature. Although, the results of the extract was not comparable to the antibiotic, as the extract contains many unknown compounds. Accordingly, identification, isolation and separation of this antibacterial agent may lead to the discovery. The methanol fruit extract of Ziziphus spinachristi was found to have good quantities of flavonoids which have possible protective effects on human health (Pawlowska et al., 2009), it was also reported that fruits of Ziziphus spina-christi have good antioxidant and anti-inflammatry effects and it was rich in bioactive phytochemicals such as tannins, steroids, flavonoids, alkaloids, glycosides and terpenoids (Alhakmani et al., 2014).

In conclusion, the findings of this result showed that the methanolic fruit extract of the Sudanese Ziziphus spina-christi has some degree of antibacterial effects and support the traditional medicinal use as a topical antimicrobial in wound healing process, although it was not comparable to the antibiotic (Chloramphenicol). However, the current study gives medical value to that fruit in addition to its nutritional importance. Since investigations on the fruit are scant, more phytochemical and pharmacological studies on the fruits of are Ziziphus spina-christi recommended in order to explore the bioactivity of this plant product.

Conflict of interest statement: We declare that we have no conflict of interest.

\section{References}

Abdalla, W.E. and Abdallah, E.M. 2016. Promising Sudanese medicinal plants with antibacterial activity-a review Article. Biol. Forum, 8(1): 299-323.

Alhakmani, F., Khan, S.A. and Ahmad, A.
2014. Determination of total phenol, invitro antioxidant and anti-inflammatory activity of seeds and fruits of Zizyphus spina-christi grown in Oman. Asian Pac. J. Trop. Biomed., 4(S 2): S656S660.

Ali, A.B., Almagboul, A.Z. and Mohammed, O.M. 2015. Antimicrobial activity of fruits, leaves, seeds and stems extracts of Ziziphus spina-christi. Arabian J. Med. Arom. Plants, 1(2): 94-107.

Arvigo, R. and Balick, M. 1994. Rainforest remedies: One hundred healing herbs of Belize. Twin Lakes: Lotus Press. New Delhi, India.

Asgarpanah, J. and Haghighat, E. 2012. Phytochemistry and pharmacologic properties of Ziziphus spina christi (L.) Willd. Afri. J. Pharm. Pharmaco., 6(31): 2332-2339.

Doughari, J.H. 2006. Antimicrobial Activity of Tamarindus indica Linn. Trop. J. Pharma. Res., 5(2) 597-603.

El-Kamali, H.H. and El-Khalifa, K.F. 1999. Folk medicinal plants of riverside forests of the Southern Blue Nile district, Sudan. Fitoterapia, 70: 493497.

El-Mahmood, A.M. and Ameh, J.M. 2007. Invitro antibacterial activity of Parkia biglobosa (Jacq) root, bark extract against some microorganisms associated with Urinary tract infections. Afri. J. Biotech., 6(11): 195-200.

Fauci, A.S., Touchette, N.A. and Folkers, G.K. 2005. Emerging Infectious Diseases: a 10-Year Perspective from the National Institute of Allergy and Infectious Diseases. Emerg. Infect. Dis., 11(4): 519-525.

Güven, K., Yücel, E. and Cetintaş, F. 2006. Antimicrobial activities of fruits of Crataegus and Pyrus species. Pharma. Boil., 44 (2): 79-83.

Houghton, P.J. 2001. Old Yet NewPharmaceuticals from Plants. J. Chem. 
Edu., 78(2): 175-184.

Kadioglu, O., Jacob, S., Bohnert, S., Naß, J., Saeed, M.E.M., Khalid, H., Merfort, I., Thines, E., Pommerening, T. and Efferth, T. 2016. Evaluating ancient Egyptian prescriptions today: Antiinflammatory activity of Ziziphus spinachristi. Phytomedicine, 23:293-306.

Omojate, G.C., Enwa, F.O., Jewo, A.O. and Eze, C.O. 2014. Mechanisms of Antimicrobial Actions of Phytochemicals against Enteric Pathogens - A Review. J. Pharma. Chem. Biol. Sci., 2(2):77-85.

Pawlowska, A.M., Camangi, F., Bader, A. and Braca, A. 2009. Flavonoids of Zizyphus jujuba L. and Zizyphus spinachristi (L.) Willd (Rhamnaceae) fruits. Food Chem., 112: 858-862.
Robinson, J. 2006. Useful wild tree resources of southern Sudan: a review. Plant Genet. Resour., 4:188-197.

Rios, J.L., Recio, M.C. and Villar, A. 1988. Screening methods for natural products with antimicrobial activity: A review of the literature. J. Ethnopharma., 23(2-3): 127-149.

Saied, A.S., Gebauer, J., Hammer, K. and Buerkert, A. 2008. Ziziphus spinachristi (L.) Willd.: a multipurpose fruit tree. Gen. Resour. Crop Evol., 55:929937.

Tom, G.M., Yesufu, H.B. and Abdulrahman, F.I. 2009. Antimicrobial screening and effect of the pulp extracts of Zizyphus spina-christi (Linnaeus Desf) on some biochemical parameters in rats. $J$. Pharm. Biores., 6(2): 58-64.

\section{How to cite this article:}

Emad Mohamed Abdallah. 2017. Antibacterial Activity of Fruit Methanol Extract of Ziziphus spina-christi from Sudan. Int.J.Curr.Microbiol.App.Sci. 6(5): 38-44. doi: http://dx.doi.org/10.20546/ijcmas.2017.605.005 